\title{
Tumor Results Evaluator Identifier
}

National Cancer Institute

\section{Source}

National Cancer Institute. Tumor Results Evaluator Identifier. NCI Thesaurus. Code C117410.

A sequence of characters used to identify, name, or characterize the evaluator of the tumor results. 